\title{
Vicente Lleó Cañal
}

El 5 de febrero de 2021 nos dejó el que fue mi gran amigo y compañero el profesor Vicente Lleó Cañal, uno de los historiadores del arte y la arquitectura más importantes del panorama español de los últimos años. Erudito y aficionado a las letras, en parte heredado de sus antepasados que ostentaron la dirección de la Real Academia de Buenas Letras sevillana. Anglófilo convencido, dominaba varias lenguas europeas además del latín y griego que hablaba y traducía en clase ante el estupor de los estudiantes. Lector y estudioso incansable obtuvo desde muy joven importantes premios antes de presentar su tesis doctoral titulada Nueva Roma. Mitología y Humanismo en el Renacimiento sevillano (1978), convertida en un clásico para los investigadores desde su publicación (1979, eds. 2001 y 2012). Su novedosa interpretación de la historiografía sevillana del Renacimiento, inició una corriente de distintas vías de investigación que permitió dar otra visión de la Sevilla quinientista, basada en sus conocimientos de la metodología de Panofsky, Warburg o Tafuri.

Vinculado como alumno y profesor a la Universidad de Sevilla, desarrolló su labor docente en otras universidades europeas y americanas entre las que siempre destacó su estancia en el Institute for Advanced Study de Princeton (New Jersey, USA) donde trabajó con el profesor Sir John Elliot al que le unió una gran amistad a lo largo de su vida. Su estancia en esta universidad le abrió nuevas perspectivas en su vida profesional y le incrementó sus ya extensas vías de investigación. Facilitó y apoyó la creación de un programa de intercambio cultural de alumnos y profesores entre Cornell University, University of Michigan y la Universidad de Sevilla que desde 1985 sigue vigente hasta hoy. Participó como miembro del equipo interdisciplinar de investigación del Centro de Estudios Históricos del CSIC y de l'Ecóle des hautes études en sciences sociales de Francia.

Su ingente producción bibliográfica ha destacado por su rigor científico, su capacidad de análisis y sus siempre interesantes visiones de determinados contextos histórico-ar- tísticos. Sus estudios se han centrado en la arquitectura y pintura de la Edad Moderna, en el coleccionismo, en las relaciones artísticas España-Italia y, en general, en el arte sevillano. Las ediciones de su libro Nueva Roma, así como los centrados en las fiestas del Corpus de Sevilla, la colección de los duques de Montpensier, el Alcázar sevillano, la Casa de Pilatos, el Palacio de Dueñas o el Palacio de la condesa de Lebrija ofrecen análisis exhaustivos del contexto histórico en el que se desarrollan las distintas trayectorias artísticas de sus componentes. Sus aportaciones a los catálogos de las exposiciones sobre Velázquez, su siempre interesante visión del coleccionismo nobiliario y, en los últimos tiempos, sus contribuciones a la historia de la religiosidad sevillana son parte de la extensa bibliografía que nos brindó en sus últimos años.

Perteneció a diversas instituciones y organismo donde desempeñó su trabajo con tesón y maestría. Vinculado a la Fundación Focus-Abengoa, patrono de la Comisión Andaluza de Museos y Artes Plásticas, de los Reales Alcázares de Sevilla y de la Fundación Casa Ducal de Medinaceli. Académico numerario de la Real Academia de Buenas Letras de Sevilla y académico correspondiente de la Real Academia de la Historia. Tuvo un relevante papel en la revista Separata que unió a diversos intelectuales de la Sevilla de los setenta que quisieron renovar el panorama artístico de la ciudad. Fue miembro asesor de diversas revistas españolas y extranjeras, entre ellas la revista Goya de la Fundación Lázaro Galdiano.

Sus conocimientos de la historia del arte se han fundamentado en una rigurosa investigación y en una curiosidad ingénita que lo han llevado a ser un lector apasionado de libros y revistas. Sus publicaciones han permitido posicionar a la Sevilla del Siglo de Oro más allá del ámbito local, buscando referentes de conexión en otros ámbitos artísticos. Ha sido una verdadera suerte para el departamento de historia del arte de la Universidad de Sevilla contar con un profesor de su talla al que siempre he considerado un verdadero

Cómo citar este artículo: HALCÓN, Fátima, «Vicente Lleó Cañal», Boletín de Arte-UMA, n. ${ }^{\circ}$ 42, Departamento de Historia del Arte, Universidad de Málaga, 2021, pp. 381-382, ISSN: 0211-8483, e-ISSN: 2695-415X, DOI: http://dx.doi.org/10.24310/BoLArte.2021.vi42.13847 
maestro y humanista en el más amplio sentido de la palabra. Su quebradiza salud de los últimos años no le impidió nunca perder la ilusión por cualquier propuesta que tuviese interés. El camino abierto en la investigación artística sevillana ha sido un incentivo para todos los que tuvimos el honor de compartir charlas y estudios con este insigne profesor. Descanse en paz.

Fátima Halcón Universidad de Sevilla 